\title{
(LUZ, CÂMERA) AÇÃO! - A EXPERIÊNCIA DE CRIAÇÃO CINEMATOGRÁFICA NO ESPAÇO ESCOLAR, MOVIMENTANDO CORPOS E SABERES
}

Daniele Gomes da Silva ${ }^{\mathrm{i}}$

\begin{abstract}
Resumo: O presente trabalho descreve processos de criação cinematográfica no espaço escolar, levados a efeito a partir de um Projeto de Extensão, e registra as experiências de deslocamentos cognitivos e físicos, haja vista que esses processos começam na mente, para se externarem por meio de movimentação, interação e ocupação dos corpos pelos espaços. Deste modo, abre-se possibilidade de (re)inventar a si mesmo e a escola, pois experimenta-se sinestesicamente o cinema. Para sustentar tais colocações, dialogamos com a Pedagogia da Criação (BERGALA, 2008) e as considerações sobre cinema e educação propostas por Fresquet (2013). A metodologia de ação adotada para desenvolvimento da investigação foi a cartografia (KASTRUP, 2008).
\end{abstract}

Palavras-chave: Criação; Cinema, Escola, Movimento, Corpo.

\section{(LUZ, CÁMARA) ACCIÓN! - LA EXPERIENCIA DE CREACIÓN CINEMATOGRÁFICA EN EL ESPACIO ESCOLAR MOVIENDO CUERPOS Y SABERES}

Resumen: El presente trabajo expone cómo los procesos de creación cinematográfica en el espacio escolar, a partir de un Proyecto de Extensión, fomentan experiencias de desplazamientos cognitivos y físicos, en vista que se inician mentalmente, pero son externalizados y posibilitados con la movimentación, interacción y ocupación de los espacios por los cuerpos. De este modo, se abre la posibilidad de (re)inventarse a sí mismo y a la escuela, pues se experimentan sinestésicamente el cine. Para sustentar tales argumentos, dialogamos con la Pedagogía de la Creación (BERGALA, 2008) y las consideraciones sobre el cine y la educación propuestas por Fresquet (2013). La metodología de acción adoptada para desarrollar la investigación fue la cartografía (KASTRUP, 2008).

Palabras-clave: Creación, Cine, Escuela, Movimiento, Cuerpo.

\section{Plano geral: a produção cinematográfica em diálogo com a indústria cultural}

Quando se fala em cinema pairam no imaginário de muitos as grandes produções hollywoodianas envolvendo cifras milionárias. Ou então, pensa-se em uma sala escura, com poltronas acolchoadas e grande qualidade sonora, em que se paga para apreciar uma produção audiovisual.

Nenhuma dessas concepções está equivocada, mas com as transformações tecnológicas algumas noções precisam ser reconfiguradas. A popularização das tecnologias digitais de 
captura e reprodução de imagens em movimento, tais como os smartphones, em concomitância com o aumento da velocidade da internet e a multiplicação de portais de publicação de vídeos de maneira gratuita, fez com que as formas de produzir e divulgar produções audiovisuais se popularizassem, dada a redução de custos para se produzir, por exemplo, um curta-metragem.

Deste modo esses novos aparatos tecnológicos de produção imagética colaboram para a expansão da concepção do que podem ser o cinema, a experiência fílmica e os espaços em que elas podem ocorrer. Além disso, mesmo as dificuldades de distribuição em espaços que gozam de prestígio social e entradas com cobranças, não desalentaram os produtores de menores recursos e outros discursos estão sendo elaborados e compartilhados na rede mundial de computadores.

Cabe notar que não se pretende desprezar a força da indústria cultural (ADORNO; HORKHEIMER, 1985), que, com suas megaproduções, especialmente as adaptações de histórias em quadrinhos, movimenta um montante robusto de capital não só por ocupar extensivamente as salas de exibição e assim, alcançar grande público, mas por produzir massivamente uma série de objetos vinculados aos personagens das tramas, que vão desde bonecos, roupas a uma infinidade de produtos licenciados. Frente a essa força acachapante, é difícil disputar. Na medida em que se tem como aliado o marketing, esses artefatos ocupam os espaços de visibilidade, e assim, se fazem "conquistar" pelo grande público.

São, pois, esses tipos de produções que se tornam populares, na medida em que são acessados massivamente, fazendo com que esse (re)conhecimento, seja determinante na formação do gosto. Isto porque, de acordo com Adorno (1983):

se perguntarmos a alguém se gosta de uma música de sucesso lançada no mercado, não conseguiremos furtar-nos à suspeita de que o gostar e o não gostar já não correspondem ao estado real, ainda que a pessoa interrogada se exprima em termos de gostar e não gostar. Ao invés do valor da própria coisa, o critério de julgamento é o fato de a canção de sucesso ser reconhecida de todos; gostar de um disco de sucesso é quase exatamente o mesmo que reconhecê-lo (p.165).

Em outras palavras aquilo que é familiar tende a ser compreendido como algo que deve ser apreciado e considerado "bom", ao passo que as alternativas ao que é massivamente propagado, o desconhecido, é rechaçado, e com isso, é considerado "ruim", "chato". A partir desses juízos de valor vai-se configurando o "gosto" da maior parte dos sujeitos. 
Ademais o contato com essas produções massivas possibilita a apreensão de valores éticos (um ethos que se reflete em formas de se portar, ser e estar no mundo), estéticos (formas de afetar e ser afetado, além de padrões imagéticos, de beleza, inclusive) e políticos (comportamentos sociais e agenciamentos). Em suma, como proposto por Wulf (2013), essas narrativas contribuem para um aprendizado cultural que ensina modos de sentir e de expressar, e que podem se apresentar enquanto processos miméticos no âmbito corpóreo e sensorial. Constituem-se assim em experiências estéticas, haja vista que afetam os sentidos e a construção do imaginário.

Como qualquer produto construído em série e em grandes quantidades, segundo Adorno (1983), perde-se a qualidade. No caso dos produtos da indústria cultural, em maioria carecem de complexidade de elaboração e caracterizam-se por serem empobrecidos em forma e conteúdo. No que concerne às produções fílmicas isto se expressa por meio de um roteiro que reproduz clichês, por uma narrativa previsível e linear, personagens rasos, e principalmente, baixa exploração dos recursos da linguagem cinematográfica. Ou seja as emoções são apresentadas de maneira explícita, bem como a tessitura de roteiro e demais elementos fílmicos, mas negligencia-se a trilha sonora, recursos de luz e sombra, coloração e movimentação de câmera, por exemplo.

Em sua maioria, a edição e a montagem destas produções são compostas por cortes curtos e rápidos que anestesiam os sentidos dos espectadores, promovendo a sensação de ação. Esses hiperestímulos e a velocidade do fluxo imagético afetam os processos perceptivos e cognitivos ao ponto de não permitir ao espectador processar tantas informações apresentadas sucessivamente. Muitas informações passam ao longo dos frames golpeando a atenção de quem vê, não se produz um registro visual e nem se tem uma experiência memorialística.

O regime de aceleração das (re)produções imagéticas faz com que os produtos visuais sejam inseridos em uma lógica de consumo. Assim, elas se fazem, necessariamente aligeiradas para que sejam consumidas e deem lugar imediatamente a outras, em um fluxo contínuo, voraz e ávido por uma representação da "realidade" que a supere, que se mantenha nova, constantemente atualizada e alcance inúmeros likes e compartilhamentos.

Progressivamente, os estímulos sensórios disruptivos transformam a experiência do olhar e os modos de ser, estar e se afetar, em suma, os processos subjetivos. A efemeridade das vivências e a quantidade de curtidas e reproduções marcam a intensidade dos acontecimentos, por meio de choques de estímulos, que ocorrem em um espaço-tempo localizados. 
Essa característica dos produtos da indústria cultural - choques perceptivos acelerados dificultam as experiências afetivas formativas, haja vista que não há tempo de elaborar, ou mesmo qualquer possibilidade de polissemia ou interpretação simbólica contidas nas obras, tamanha a rapidez com que elas se apresentam. Adorno aponta que a perda da capacidade de fazer experiências formativas não é um problema imposto de fora à sociedade, acidental, e nem é provocado por intenções subjetivas, mas corresponde a uma tendência objetiva da sociedade, ao próprio modo de produzir-se e reproduzir-se da mesma (ADORNO, 1995, p.26). No mesmo sentido:

\begin{abstract}
Aos poucos, ainda que numa velocidade que pode impedir a compreensão dos sentidos dos processos, ao lhes escamotear a densidade da experiência, desmorona-se toda a arquitetura psicofísica que sustentava aquele protagonista dos velhos tempos modernos. Saem de cena, assim, um tipo de corpo e um modelo de subjetividade cujo cenário privilegiado transcorria em fábricas e colégios, e cujo instrumental mais valorizado era a palavra impressa em letras de fôrma (SIBILIA, 2012, p.49).
\end{abstract}

Desse modo acompanhamos uma transição de processos analógicos e voltados para o domínio da palavra para movimentos digitais e vinculados às imagens, tanto metafóricas quanto literais. Assim cada vez mais (re)produzir e propagar imagens em um fluxo contínuo reverbera em nossos corpos, subjetividades e nos modos de ser e estar no mundo (SIBILIA, 2012).

É nesse contexto que se inserem os sujeitos e os processos educativos na contemporaneidade, em um espaço-tempo limítrofe entre a cultura letrada e a digitação virtual, a temporalidade da analógica e a (re)produção imagética voraz e acelerada.

\title{
Plano detalhe: as configurações escolares na contemporaneidade
}

Somos perpassados pelos novos modos de atuação dos regimes cognitivo e atencional, que sofrem alterações propulsionadas pela relação dos indivíduos com as novas tecnologias digitais de comunicação. Mas, ao ingressar na escola, os estudantes são convocados a atuarem de outra maneira, a imergirem em um outro tempo e em outras regras comportamentais. Diferentemente das solicitações de outros espaços sociais, exteriores aos muros da escola, alguns modi operandi que estão mais alinhados ás solicitações da sociedade de controle 
(DELEUZE, 2013), faz com que ela seja afastada da multiplicidade das demandas sociais. Com isso, emerge uma tensão entre a atenção e o espaço escolar, que se mantém com marcas da modernidade e da sociedade disciplinar (FOUCAULT, 1977), representadas pela predominância da linguagem escrita e de um modelo de racionalidade marcadamente cartesiano, que separa o corpo (forjado em experiências sensíveis, que podem ser enganosas) e a mente (espaço em que se elaboram ideias claras, distintas e verdadeiras).

O espaço escolar pode ser um lócus privilegiado de encontro geracional em que os sujeitos mais velhos apresentam o velho mundo aos mais jovens (ARENDT, 2000). Ademais, para além da iniciação temporal entre o antigo e o novo, nesse encontro seriam fomentados modos de possibilitar espaços e tempos para recriar, a partir de outras lógicas, a configuração ao mundo recém-chegado.

A escola, por ser também um significativo ambiente de socialização, espaço de condições de possibilidades e relações de poder, sente os reflexos sofridos por esses corpos e subjetividades. Afinal as mudanças sociais, históricas e culturais transformam as subjetividades, na medida em que elas se constroem nas práticas cotidianas de cada cultura, os corpos também se esculpem nesses intercâmbios (SIBILIA, 2012, p. 10).

Nas instituições educacionais essas mudanças são visibilizadas pois, de um lado, alguns resquícios da modernidade se mantêm, como por exemplo a vigilância e o controle, a estrutura marcada pela distribuição dos corpos em determinado espaço, a execução de tarefas definidas e cronometradas pelo tempo, com certa expectativa comportamental e parâmetros enrijecidos a serem seguidos. Por outro lado, circulam corpos e subjetividades não mais configurados ao regime disciplinar, mas hiperestimulados e acelerados.

A escola, essa tecnologia de época (da modernidade), que pretendia educar o povo, ofertando aprendizagens úteis e práticas, além de incutir valores pela disciplina, docilizava e condicionava os corpos por meio do confinamento delimitado por paredes, grades e fechaduras, intervalos regulares, circunscritos e com pausas restritas (FOUCAULT, 1977). No entanto, por mais que essa arquitetura se mantenha, as tecnologias eletrônicas e digitais e suas interfaces de uso fazem com que os indivíduos escapem dessas estruturas e se conectem em redes (sociais, virtuais) uns com os outros, tenham acesso às mais diversas informações e percebam a realidade que os cerca de outra forma, muito mais imagética, e que extrapola os limites das paredes e da ordenação disciplinar.

Em consonância com esse processo de transição, os dispositivos eletrônicos comunicacionais de uso cotidiano, como tablets e smartphones, convocam de seus usuários 
rápidas adaptações corporais e subjetivas aos novos ritmos de experiências, permitindo responder com a maior agilidade possível à necessidade de reciclagem constante e de alto desempenho (SIBILIA, 2012, p. 51). Isto porque, na sociedade de controle, há necessidade de formação permanente e controle contínuo, pois "nunca se termina nada" (DELEUZE, 2013, p.226).

É importante entender que esses novos suportes de informação e comunicação móveis, e principalmente, a ação de produzir imagens de si e do mundo, já foram incorporados pelos indivíduos que transitam por esse espaço educacional, ou seja, este espaço encontra-se "hibridizados", pela presença de elementos modernos e de elementos contemporâneos. Neste contexto não adianta rechaçar o uso desses equipamentos no ambiente escolar, sob pena de aumentar a cisão entre o ambiente escolar e as demais esferas da vida dos estudantes. Sendo assim, não cabe fazer uma ode à tecnologia ou aceitar de maneira resignada tais elementos, mas, sim, propor modos de operacionalizá-los, antes que sejamos controlados por seus modos de funcionamento.

Práticas cotidianas e culturais são afetadas por esse novo regime de atenção que esculpem corpos e produzem subjetividades hiperestimuladas sensorialmente e inseridas em modulações de aceleração, que experienciam outras formas de ser e estar no mundo. Afinal a recepção estética é marcada pela instabilidade, e o corpo do indivíduo passa a ser tema de experimentações e novos discursos que tentam regular e controlar os atores sociais, na medida em que esse corpo é mais um componente que circula e constitui o espaço.

O corpo é a sede da visão, da atenção e da estimulação. Talvez, por essa razão, ele ocupe lugar de destaque nas produções imagéticas, seja erotizado e o tornado objeto de desejo, seja moldado e modificado para ser exposto e curtido, ao ponto de se confundir com mais um, dentre tantos outros, produtos em série.

No entanto, ocorre um fenômeno que busca promover processos de desmaterialização da visão, como se esta fosse uma entidade para além do corpo, ou seja, descorporificada (CRARY, 2015). Ao mesmo tempo que o corpo deve ser voltado para o trabalho industrial, parece que a visão, sentido que recebe a cultura e as produções em massa das mídias, se distrai em espetáculos visuais ou em redes sociais com intensas interfaces imagéticas, que atuam como alento ao desgaste da força física promovido pela rotina exaustiva do trabalho.

Outrossim, esta suposta distração é capitalizada e a exposição que os sujeitos fazem de suas vidas gera lucro para megacorporações. Mapeiam-se pequenos nichos de consumo e 
ofertam-se produtos direcionados para a composição de cada tipo de subjetividade, tendo como finalidade maior aceitação nos grupos sociais de viés identitário.

Assim, percebemos a relação entre o contexto socio-histórico e os processos subjetivos, na medida em que se entende que, a visão e seus efeitos são inseparáveis das possibilidades de um sujeito observador, que é a um só tempo produto histórico e lugar de certas práticas, técnicas, instituições e procedimentos de subjetivação (CRARY, 2015, p.15).

Nesse contexto de organização social do trabalho imerso nessas novas configurações sociais, podemos perceber como a revolução industrial modificou não apenas o sistema de produção material, mas também os modos de ser e estar no mundo. Afinal, é no fim do século XIX que as mais variadas técnicas de reprodução sem limite a produção em massa são impulsionadas, conforme nos fala Walter Benjamin (1994). As técnicas modernas geram mudanças na sensibilidade e na forma de produzir arte, fazendo com que o espectador, inserido nessa nova lógica social, busque novas experiências estéticas, por conta dos estímulos da sociedade de consumo e o cinema, enquanto uma arte de massa, por excelência, se adequa perfeitamente a essas configurações.

\section{Plano sequência: uma cartografia das possibilidades do cinema na escola}

Paulatinamente é possível perceber que os estímulos imagéticos provocam transformações cognitivas e os hiperestímulos sensoriais, com ênfase nos estímulos visuais, modificam a atenção, criando assim uma tensão no espaço escolar. Nesse contexto, como forma de promover um processo reflexivo entre a produções imagéticas dos sujeitos que transitam pelo espaço escolar e os modos de ser e estar no mundo, frente aos novos processos subjetivos, apostamos no fomento da criação cinematográfica, como por exemplo as experiências viabilizadas pelo programa de extensão universitária Cinema para Aprender e Desaprender (CINEAD

${ }^{2}$ ), que ocorrem na Escola de Cinema do Colégio de Aplicação da Universidade Federal do Rio de Janeiro (CAp UFRJ), instituição federal localizada no município do Rio de Janeiro. Criado em 2008, o projeto de extensão faz parte das ações que são triangulares com atividades de ensino e pesquisa no Laboratório de Educação, Cinema e Audiovisual (LECAV) da Faculdade de Educação da Universidade Federal do Rio de Janeiro (FE-UFRJ). Nele, investigam-se as 
possibilidades e questionam-se as aprendizagens a partir da experiência de fazer cinema em instituições públicas de educação, o que permite a interação entre universidade pública e educação básica. Em vista disso, cabe ressaltar tratar-se de ações que buscam promover experiências disruptivas ao desnaturalizar regimes de visualidade, sem pretensões de estabelecer uma hierarquia entre sujeitos conscientes e aqueles que precisam ser emancipados.

Esse movimento de intercâmbio entre educação e cinema tem como principal referência a proposta de Alain Bergala, crítico e cineasta francês que entre 2000 e 2002 foi conselheiro do Plano Pedagógico de Cinema implementado nas escolas públicas da França. Sua proposta chama atenção por entender o cinema como arte, e por isso como um outro conhecimento, modo de pensar, se expressar, dentro do espaço escolar. São testemunhos da força política da proposta.

Para mapear as experiências do CINEAD no Colégio de Aplicação escolhemos o método da cartografia (DELEUZE, GUATTARI, 1995; KASTRUP, 2008; 2007), por entender que o foco está nos acontecimentos, nos encontros, nas potências, nas provocações que ocorrem e nos elementos que emergem, favorecendo o acompanhamento dos processos cognitivos e os deslocamentos vivenciados pelos sujeitos envolvidos.

Essa abordagem metodológica possibilita a percepção de que toda pesquisa também é invenção, e que nem território nem pesquisadores estão fechados, definidos, pré-dados, mas, sim, vão se constituindo com o processo investigativo, com as intervenções no espaço, com as produções de subjetividades e com a emergência dos conhecimentos, haja vista que território, objeto e sujeitos estão engendrados.

A cartografia, método proposto por Deleuze e Guattari $(1995,1996)$, é utilizada em pesquisas que se voltam para o estudo da subjetividade, pois tenta lidar com a complexidade, a partir de uma leitura esquizoanalítica ${ }^{3}$ da realidade, na qual se busca acompanhar a processualidade dos acontecimentos e não alcançar respostas dadas. Essa perspectiva se baseia na invenção e na maneira em que o pesquisador está implicado na percepção dessa produção ${ }^{4}$.

Ele busca captar os processos e seus movimentos, ritmos, velocidades e, sobretudo, seus pontos de intensidade e de problematização (KASTRUP, 2008, p.269), não visando interpretações ou buscando sentidos, mas sim o encontro com o que há de problemático, de perturbador, de estranho, de imediato e de singular. Acolhendo o inesperado, o estranhamento, o surpreendente e todas as demais figuras da invenção de problemas.

Atua-se por um viés das multiplicidades, dos devires, dos acontecimentos, do exercício do pensamento enquanto ele se processa, sem finalizações, modelos, e metas pré-estabelecidas. Não sendo assim 
um método que vise a apresentar uma análise exaustiva ou totalizante, mas busca circunscrever um plano coletivo de sentidos, sistemas e signos (DELEUZE, 1987), que não desenham uma identidade, mas, ao contrário, permite detectar os elementos de processualidade do território em questão. Os sistemas de signos não são objetos ou características subjetivas, mas do grupo, das linhas ou forças em jogo no processo em curso (KASTRUP, 2008, p.274).

Assim, acompanhamos os mais de 25 encontros ocorridos às segundas feiras à tarde, com duração de 2 horas, em um grupo composto por 23 estudantes entre 10 e 13 anos de idade.

A principal proposta do CINEAD é proporcionar uma experiência de introdução ao cinema no espaço escolar, como forma de abrir outro espaço de enunciação e principalmente de criação de exercícios e ensaios visuais, com inspiração sempre na sétima arte. Para tal levamos trechos de filmes de Godard, Kiarostami, Mélies e também exibimos curtas nacionais como O Som Que Vem da Ilha ${ }^{5}$, O Fim do Recreio ${ }^{6}$, O Filho do Vizinho ${ }^{7}$, Águas de Romanza ${ }^{8}$.

Espera-se que o encontro com este outro repertório amplie os modos de ser e perceber o mundo e que as experimentações levem a outros caminhos, saberes e vivências, pois elas mobilizam os participantes a criarem produções imagéticas que também ativam desejos, sentidos e afetos dentro de um espaço que lhes é cotidiano. Além de convocar outra forma de perceber a realidade, pois solicita aos intelectos e aos corpos que se portem de uma nova maneira e alterem o modo pelo qual circulam no espaço. Passa-se deste modo a ressignificar e a (re)descobrir outras possibilidades para o que outrora havia sido banalizado, transformando a percepção de si, do mundo e do Outro.

Para tal, parte-se dos gestos de:

$1^{\circ}$ Enquadrar, $2^{\circ}$ Fazer de conta e tomar decisões, $3^{\circ}$ Ensaiar modos de ver: construir pontos de vista, $4^{\circ}$ Ensaiar modos de ouvir: construir pontos escuta, $5^{\circ}$ Ocultar/revelar, $6^{\circ}$ Colocar em relação, $7^{\circ}$ Crer/duvidar, $8^{\circ}$ Descronologizar e intensificar o tempo, $9^{\circ}$ Inventar, $10^{\circ}$ Criar sentidos (FRESQUET, 2013, p.91).

Com isso buscamos explorar os sentidos e as possibilidades de criação que se dão através do uso da câmera. Interessa-nos também mobilizar e fazer emergir outras habilidades no exercício de criação, que nem sempre são valorizadas no sistema escolar, pois no fazer cinematográfico há espaço para o movimento, para a fala, para a invenção e para a relação que há entre as experiências coletivas compartilhadas e a dimensão individual, ou seja, o modo que cada sujeito apreende a vivência fílmica. Como cada corpo se desloca e compõe um elemento 
de saberes e aprendizados, se entende que ver cinema e fazer experiências dessa arte renova, no aprendizado, a vitalidade do aprender, como ação e movimento (FRESQUET, 2013, p.10).

Nos encontros, havia três momentos: a retomada do que foi exercitado no encontro anterior e exibição das produções finalizadas, para dessa forma (re)vermos e comentarmos o que fora produzido; exibição dos filmes ou fragmento postos em relação e discussão do que foi visto; a proposição do exercício do dia e o momento de produção ${ }^{9}$, em que os participantes discutem, inventam e capturam as imagens de si, do Outro e do mundo, a partir de alguma categoria estabelecida, como o uso de uma cor, um sentimento, uma luz, um ângulo. Tal categoria não é um limitador, mas sim uma "regra", que coloca uma situação de crise e desafio, e atua como um dispositivo direcionador para a criação.

Pensando em formas de recriar a multiplicidade do espaço escolar, no início dos encontros da Escola de Cinema do CAp, criávamos uma ambiência, para auxiliar a reconfiguração territorial, num espaço que se distanciasse da noção usual de sala de aula, para que ela fosse transmutada e ampliada. Os filmes eram projetados na parede para que pudessem expandir as dimensões. Dessa forma, para visualizá-los, era necessário que os estudantes virassem as carteiras de costas para o quadro branco, local onde normalmente fica o conteúdo abordado em aula.

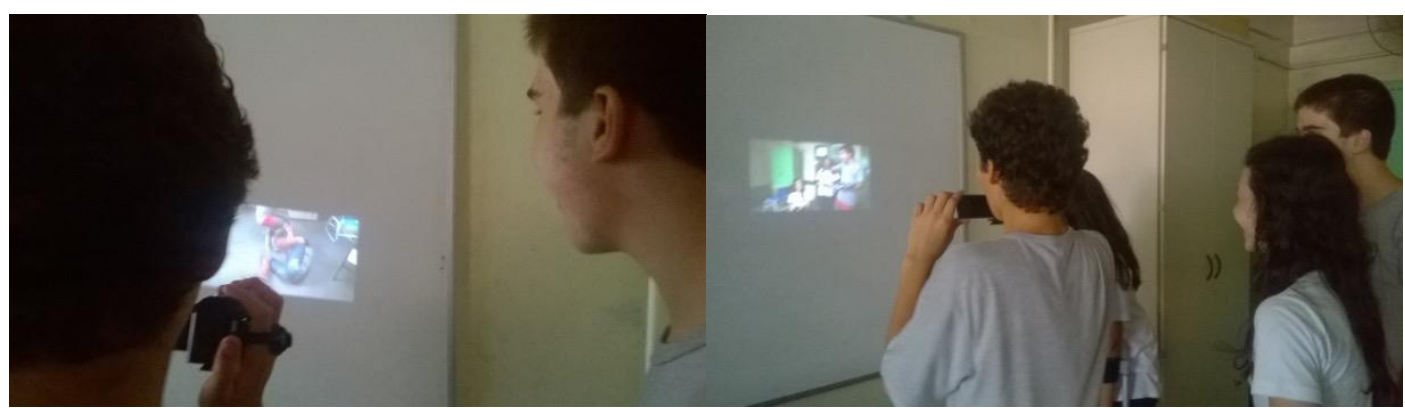

Figura 1 e 2: Estudantes projetando as imagens capturadas no quadro branco, espaço costumeiramente destinado aos conteúdos escolares, num gesto de desordenação. Fonte: acervo pessoal. 


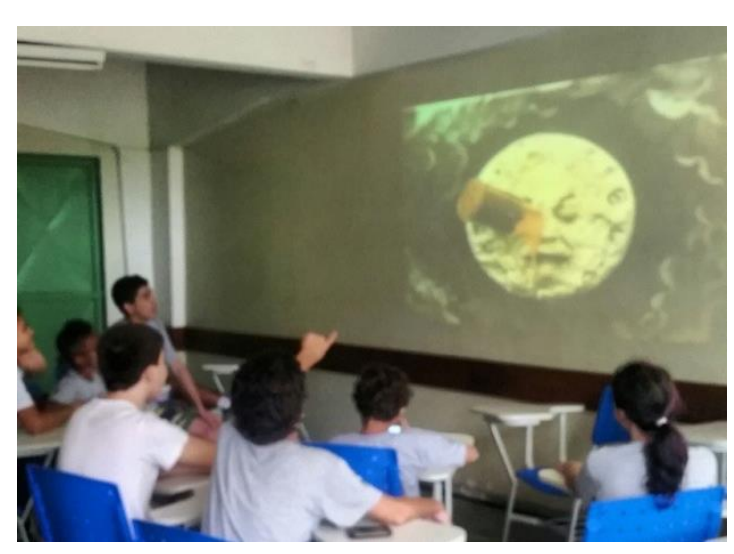

Figura2: Exibição do filme Viagem à Lua, em que estudante aponta para foguete que, na narrativa, saiu do planeta Terra e "aterrissou" na Lua.

Assim a parede se tornava uma tela de exibição e os corpos dos estudantes se posicionavam da maneira que achavam mais confortável, assumindo posições bem diferentes das que têm nas aulas das disciplinas escolares. Aos poucos íamos desacelerando e criando a atmosfera de um outro regime atencional. As falas e a agitação tornavam-se pausas e silêncios para a exibição do filme e desatenção do cotidiano. Nesse momento, entrava-se em outro território. E, por mais que a sala onde aconteciam os encontros tivesse as configurações usuais, nesses momentos, algumas posições eram modificadas. Com isso notamos que a entrada no cinema na escola e a exibição do filme de forma ampliada já provocava deslocamentos físicos.

A partir dessa outra forma de ocupar o espaço, inicialmente destinado às aulas de Línguas Estrangeiras, podemos pensar em como esse lócus podia se tornar um o território inventado, que permutava de sala de exibição fílmica, estúdio de gravação (que se desdobrava desde uma mesa de emissão de um jornal até uma casa mal assombrada), refeitório (pois, muito estudantes usavam o espaço para fazerem suas refeições) e até sala de concertos para piano.

No sentido de buscar diversas formas de materializar os processos criativos, ampliar o repertório de referências culturais dos estudantes e exercitar a criação artística em sua potencialidade cognitiva e em suas diferentes formas de expressão, é que propusemos aos estudantes corporificar e dialogar com duas formas de arte e a interagirem com tintas, pincéis e cavalete.

A inspiração se deu a partir de fragmentos do filme $O$ Mistério de Picasso $^{10}$, de HenriGeorges Clouzot, onde o pintor cria vinte telas e o cineasta acompanha os momentos de atuação de sua misteriosa criatividade, filmando do lado inverso das telas que eram pintadas. Para tal 
foram utilizadas tinta e papel especiais e, nas pinturas a óleo, as imagens eram exibidas pela técnica de animação stop-motion.

Ao que se sabe, todas as obras criadas para o filme foram destruídas, quando ele foi finalizado. $\mathrm{O}$ interessante desse filme é que ele mostra o processo de criação quase que em tempo real, evidenciando a processualidade que envolve o gesto criativo, além de fazer ver que a criação das obras demanda trabalho, tempo, espera. Que é necessário "observar, ver e depois começar a imaginar, trocar a passividade pela atividade" (CARRIÈRE 2015), para só então, a criação começar a se materializar. Acreditamos que esses ensinamentos são muito caros ao gesto de criação cinematográfica. Além disso, o filme proporcionou o encontro com um grande pintor e sua obra.

O filme tem imagens tão vigorosas que, durante sua exibição, houve um silêncio sepulcral e tamanha atenção focada, concentrada e aberta, que até mesmo uma cartela de informações finais, que estava em inglês, os estudantes quiseram que fosse pausada, para que pudessem traduzi-la. Esse gesto nos dá uma pista do quanto tinham desejo de aprofundar sua compreensão a respeito do que foi visto, tanto no que diz respeito aos elementos imagéticos quanto aos elementos textuais.

Começaram, em seguida, a expor, muito empolgados, suas impressões a respeito do que fora visto. Em suas falas comentavam a postura do pintor e a temporalidade do filme, que levava a acompanhar o que ele "tava fazendo", bem como seu maravilhamento ao verem as obras surgindo nas telas, e na própria tela de projeção, que, anteriormente em branco, ia ganhando cores e outras intensidades.

Os estudantes foram então convidados a pintarem telas e capturarem esse processo criativo, explorando as diversas posições de câmeras e construindo assim diversos enquadramentos e pontos de vista. Dividiram em dois grupos, onde, no primeiro momento, um grupo deveria pintar enquanto o outro captava esse momento de exterioridade criativa. No segundo momento, essa função deveria ser cambiada. Tal exercício foi muito interessante, pois envolvia duas expressões artísticas com diferentes processos criativos e com características de linguagens muito próprias, colocadas em relação por meio do gesto criativo.

Ao longo do desenvolvimento da atividade foi possível observar a adesão dos estudantes à proposta de exercício. Um deles, em especial, parecia querer exercer todas as funções, executando com extrema seriedade a proposta. Mas todos pareciam estar imersos, num misto de absorção e ludicidade, participando e colaborando para a produção audiovisual inspirada no 
filme que acompanhava o processo criativo e produtivo de Picasso. Talvez, porque tivessem plenamente envolvidos para que o gesto criativo ocorresse.

Assim foi possível observar a abertura que as artes possibilitam em relação à alteridade, baseada no tripé mundo, eu e Outro, haja vista que um eu se expõe e interage com outrem, compartilhando sua percepção de mundo e entrevendo a possibilidade de transformação. Pois os sujeitos se voltavam para si, exteriorizavam-se em cooperação com os outros, tendo como inspiração a afetação com obras produzidas em outro espaço tempo que não o seu, mas que lhes tocava.

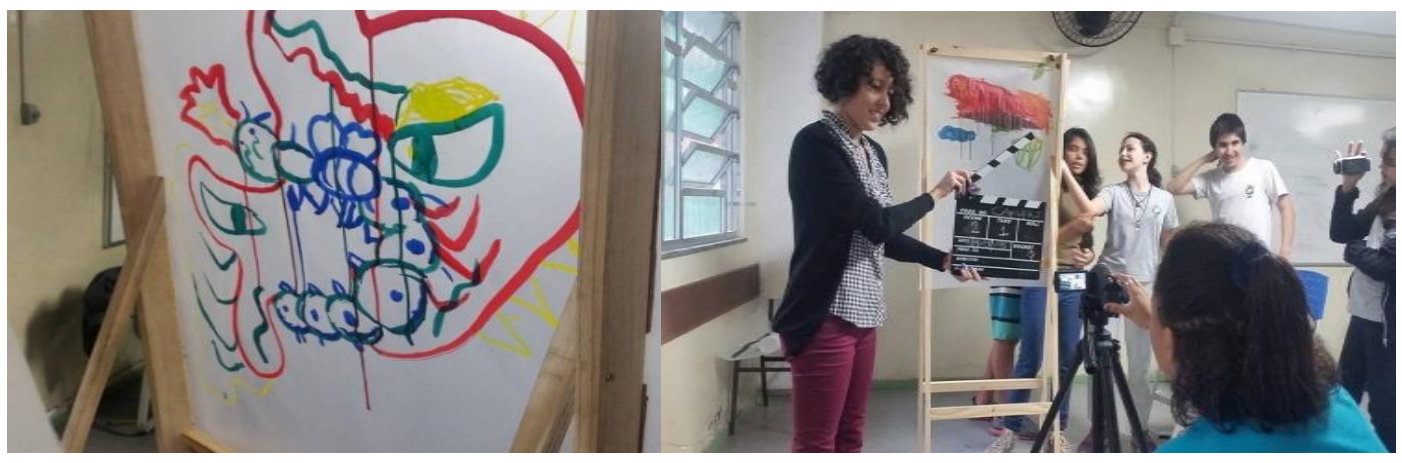

Figura 4: Frame de uma das cenas capturadas por um dos grupos em que a pintura é captada do lado oposto onde foi pintada, deixando-a em primeiro plano, tal qual no filme O Mistério de Picasso.

Figura 5: Grupo pintando enquanto outro, fazendo uso de duas câmeras, captura os momentos do processo criativo, fazendo ver tanto o que está sendo produzido por um ângulo como gestos de criação de outro. Pode-se ver também o uso da claquete como elemento cinematográfico.

Com essa experiência, podemos pensar em uma concepção ampliada da cognição, que não se limita a pensar a solução de problemas, mas que é compreendida enquanto processo cognitivo que ressignifica e amplia as possibilidades de interação e invenção do eu e do mundo, como nos fala Virginia Kastrup (2004), que inventa e cria sentidos. Na medida em que não se atém a regimentos e princípios enrijecidos entre um sujeito e um objeto dados, como se as concepções de eu e de mundo pudessem ser determinadas, a atenção passa a ser considerada uma prática de invenção de regimes cognitivos diversos, co-engendrando, ao mesmo tempo, o si e o mundo, que passam à condição de produtos do processo se invenção (KASTRUP, 2004, p.159). Nesse sentido a cognição agrega também a invenção de problemas e não mais apenas uma possível solução, rompendo com a usual relação de passividade frente aos acontecimentos.

Percebemos então que o fazer cinema exige o reposicionamento dos corpos e que se percorram novos percursos cognitivos. Dessa maneira é possível fazer redescobertas dos espaços escolares, haja vista que, para captar determinada imagem de determinado ângulo, é 


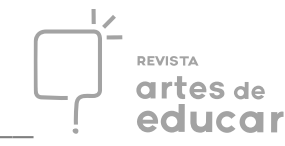

necessário explorar as posições dos corpos, os lugares e as formas com que eles se portam. $\mathrm{Na}$ busca por explorar as formas de capturar as imagens, os corpos adquirem novas posturas, para que as imagens, outrora mentais, pudesse ser capturada e posteriormente, compartilhadas.

Nesse processo percebemos que a atuação cognitiva não é apenas um processo mental (KASTRUP, 2008), mas se realiza quando os corpos atuam e inventam um novo modo de se portar e de perceber a realidade que os circunda, haja vista que o corpo é um ente participante no mundo que promove conexões entre o eu, individual e a alteridade, coletiva.

Tal proposta de conhecimento coloca o corpo em cena e propõe que o gesto de conhecer está no âmbito existencial, onde "conhecer é viver", isto é, saber problematizar, interagir, experimentar com os devires, manter-se aberto, sensível e inventivo à possibilidade de novos acoplamentos e a construção de aprendizados.

\section{Cenas finais e alguns caminhos percorridos}

O espaço escolar, a exemplo do que acontece com outros espaços institucionais, retém elementos da sociedade industrial, e os sujeitos circulam concomitantemente por esses espaços e aqueles atravessados pela tecnologia e demais elementos contemporâneos. A escola se empenha em absorver algumas dessas novidades em seu currículo pedagógico, mas não em profundidade e celeridade suficientes, uma vez que corpos dóceis e passivos são ainda pressupostos de sua atuação. A exemplo, sua configuração espacial se propõe a uma ordenação rígida e existem ainda diversos mecanismos de controle, disciplina e punição na instituição escolar. Além disso, as formas de se relacionar com os saberes e com a produção de conhecimento se mantêm restritas às da época moderna, quando o rigor, a cientificidade e a habilidade escrita eram extremamente valorizados.

Acreditamos que as atividades de produção cinematográfica no espaço escolar fomentam outras experiências do olhar, do pensar, do ser e do conhecer. Pois nelas os estudantes trabalham em equipe na construção do filme e exercitam, ao mesmo tempo, atitudes como a responsabilidade, a tomada de decisões, a criatividade, a coerência e a coesão, e também o improviso, a solução de problemas, a interação, a imersão numa outra temporalidade e num outro regime atencional.

Estas experiências repercutem em seus corpos e em suas subjetividades, haja vista que são convocados, a cada encontro, a uma experiência diferente e inesperada de produção 
imagética, em que a partir do tema proposto, eles têm que expressar visualmente as problematizações. Nessas experiências se constrói um jogo que mobiliza as partes envolvidas a aprender, desaprender e reaprender, por meio dos gestos de escolher, tomar decisões, atitudes que permeiam a prática cinematográfica e ecoam em outras esferas da vida humana. Para filmar, é necessário parar, pensar, experimentar, definir os elementos que serão capturados pela câmera, desautomatizando a produção de imagens.

Se a indústria cultural

determina toda a estrutura de sentido da vida cultural pela racionalidade estratégica da produção econômica, que se inocula nos bens culturais enquanto se convertem estritamente em mercadorias; a própria organização da cultura, portanto, é manipulatória dos sentidos dos objetos culturais, subordinando-os aos sentidos econômicos e políticos e, logo, à situação vigente (ADORNO, 1995, p.21)

Alternativa aos produtos massificados que dificultam experiências intensas e formativas, o encontro do cinema na escola pode partilhar de outros sabores. De fato estímulos imagéticos provocaram transformações cognitivas, mas principalmente por acreditar que o cinema possui importante papel ético, estético e político, ao expor visões e mundo e versões possíveis da realidade.

Sendo o gosto uma construção social, sua formação passa por um processo de cultivo e a escola pode contribuir positivamente para este processo por meio da exibição de bons filmes, aqueles de reconhecido valor artístico e cultural, fruto de roteiros bem elaborados e bem filmados, com a densidade e complexidade que caracterizam obras-primas, tornadas clássicas pela história e pela durabilidade (BERGALA, 2008), que se afastam dos produtos massificados da indústria cultural.

Por isso no encontro com o cinema no espaço escolar, não se deve partir de um suposto "gosto" dos estudantes para só depois introduzir obras com outros padrões estéticos, pois o cinema na escola deve dar preferência a filmes que estudantes não teriam chance de encontrar fora dela.

O gosto é fruto do cultivo e não se dá de forma espontânea, cada um gosta de determinada coisa porque teve acesso a ela. O apreço é formado pela acumulação de cultura, tempo e memórias; nesse sentido a proposta de iniciação ao cinema também visa a fornecer um capital inicial de filmes capazes de constituir uma alternativa ao cinema de puro consumo (BERGALA, 2008, p.91). 
Assim a escola deve estar presente na construção do gosto, promovendo o encontro da alteridade fundada sobre a obra de arte.

\begin{abstract}
A proposta de iniciar as crianças em um tipo de cinema não comercial não tem qualquer relação com arrastá-las do lugar comum para outro lugar. Uma proposta de formação do gosto parte exclusivamente do encontro com a alteridade fundamental da obra de arte, com o desconforto e o choque que ela provoca (FRESQUET, 2013, p. 49)
\end{abstract}

Por meio dessas interlocuções, podíamos perceber, em nosso experimento, como o cinema atuava como outro que adentra esse território, reconfigurando os espaços-tempos dados, para o território da arte; desestabilizando, educando e fazendo pensar (XAVIER, 2008), haja vista que, o cinema que "educa" é o cinema que faz pensar, não só o cinema, mas as mais variadas experiências e questões que coloca em foco (p.15).

Sob essa perspectiva, entendemos que o cinema pode expandir sua atuação, de concepção de "transmissor de conteúdos" para profanador de espaços, perturbador de status quo, provocador de reflexão, que possibilita questionar constructos históricos, tomados como naturais, inquestionáveis, na medida em que atua disparando os mais diversos desaprendizados. Talvez, a função educativa do cinema esteja em proliferar infinitas conexões para o desejo, ensinar diferentes formas de pensar-sentir-dizer e estar no mundo, desterritorializar o pensamento, levar o corpo a devir-outro (DINIS, 2005, p.78).

Quanto mais a educação procura se fechar ao seu condicionamento social, tanto mais ela se converte em mera presa da situação social existente (ADORNO, 1995, p.11): para fugir a este dilema, é necessário dialogar com outras instâncias sociais, permitir que novas maneiras de ser e estar no mundo emerjam, e que os sujeitos que transitam pelo espaço escolar encontrem outros modos de se expressar e de expressar o mundo, pois a estrutura da indústria cultural "forma, formata, deforma, informa". Ela se presta a divulgar ideologias e dirigir de maneira equivocada a consciência dos espectadores. (ADORNO, 1995, p.77).

E, por mais que o cinema seja mais um de seus produtos, ele desenvolve uma competência de ver, e, uma certa disposição, valorizada socialmente, para analisar, compreender e apreciar qualquer história contada em linguagem cinematográfica (DUARTE, 2009, p.13). Tal linguagem não é adquirida apenas vendo filmes, o ambiente de artefatos culturais nos quais os sujeitos estão inseridos, também interfere, incluindo as vivências escolares e a afinidade com as artes. Além disso, o cinema, bem como a escola, é um importante 
espaço tempo de socialização, oportunidade de colocar os sujeitos e seus corpos em movimentos.

Os novos meios de comunicação de massa e os suportes tecnológicos digitais portáteis facilitam o volume de troca e propagação de imagens, e tal excesso pode levar a uma dessensibilização. Assim o gesto de fazer cinema provoca uma desaceleração e outro tipo de atenção é convocado a atuar em um outro tempo. Tempo este que é diferente do solicitado nas disciplinas escolares. Dessa forma, o cinema atua como um compatibilizador entre a velocidade das demandas sociais e o ritmo solicitado pela escola.

Assim quando estudantes são convocados a atuarem, suas produções propiciam um ciclo de aprendizagem que se inicia por um processo mental (quando imaginam e projetam suas produções), se desloca para a movimentação corporal e é finalizada com um gesto criativo de concepção da obra, simbolizando desejos e produzindo afetos ao vivificar o ato da criação, podemos perceber como o SER=FAZER=CONHECER se apresentam imbricados ao processo de produção de si e invenção de mundo.

Afinal,

o cinema e a educação talvez possam fazer alianças pela capacidade de cada um desses campos afetar o outro, não ilustrando, o que seria a repetição do mesmo, mas porque o cinema pode conduzir a educação a novos lugares, a pensar o diferente, pode afetar produzindo um estado de ruído, de estranhamento na função comunicativa da educação de modo a levá-la a novos devires, à emergência de um novo tempo. (DINIS, 2005, p.69)

Desse modo, o uso pedagógico da imagem e a produção imagética pode auxiliar na reconfiguração e abertura para novas possibilidades de aprendizagens, onde a ocupação dos espaços-tempos simbólicos legitimam o direito à livre experiência do sensível, da imaginação e da fruição.

O cinema, a partir da produção de imagens faz pensar o impensável, agrega o pensar com o corpo, provocando órgãos e sentidos a aflorarem de outras formas. O tato se abre para tocar o intocável; a visão, enxerga o invisível; a audição, escuta novos silêncios, ruídos, sons; o olfato percebe novos aromas e odores; o paladar degusta novos sabores e saberes; e todas as demais formas de sentir e perceber a si e ao mundo tomam novos rumos, novas formas, novos sentidos. Trata-se de ressignificar o que outrora era familiar, banal, invisível, insensível. 
A partir das práticas cinematográficas, a atenção toma novos rumos. Ela deixa de ser entendida como um processo de organização e representação de informações e dá lugar a conceituação de problematização e estranhamento, que possibilitam uma aprendizagem inventiva.

\section{REFER $\hat{E} N C I A S$}

ADORNO, T. W. O fetichismo na música e a regressão da audição. Coleção Os Pensadores. 2. ed. São Paulo: Abril Cultural, 1983.

ADORNO, T. W. Educação e emancipação. Editora Paz e Terra. 1995.

ADORNO, T. W.; HORKHEIMER, Max. Dialética do esclarecimento. Rio de Janeiro: J. Zahar, 1985.

ARENDT, H. A crise na educação. In: ARENDT, Hannah. Entre o passado e o futuro. São Paulo: Ed. Perspectiva, 2000.

BENJAMIN, W. A obra de arte na era de sua reprodutibilidade técnica. In: Magia e técnica, arte e política: ensaios sobre literatura e história da cultura. 7 Ed. São Paulo: Brasiliense, 1994.

BERGALA, A. A hipótese-cinema: pequeno tratado de transmissão do cinema dentro e fora da escola. Rio de Janeiro: BookLink, 2008.

CARRIÈRE, J. C. A linguagem secreta do cinema. Rio de Janeiro: Nova Fronteira, 2015.

CRARY, J. Técnicas do observador: visão e modernidade no século XIX. Rio de Janeiro: Contraponto, 2015

DELEUZE, G; GUATTARI, F. Mil Platos. V.1. São Paulo: Editora 34, 1995.

DELEUZE, G. Conversações. 3 ed. São Paulo: Editora34, 2013.

DINIS, N. F. Educação, cinema e alteridade. In: Educar. Curitiba: Editora UFPR,n. 26, p. 67$79,2005$.

DUARTE, R. Cinema e Educação. Belo Horizonte: Autêntica Editora, 2009. 3. Ed.

FOUCAULT, M. Vigiar e Punir. Rio de Janeiro: Vozes, 1977.

FRESQUET, A. M. Cinema e educação: reflexões e experiências com professores e estudantes de educação básica, dentro e "fora" da escola. Belo Horizonte: Autêntica Editora, 2013 . 
KASTRUP, V. O método da cartografia e os quatro níveis da pesquisa-invenção. In: Lucia Rabello de Castro e Vera Lopes Besset (Org.). Pesquisa-invenção na infância e juventude. Rio de Janeiro: Nau, 1ed, v.1, 2008.

KASTRUP, V. O funcionamento da atenção no trabaçho do cartógrafo. In: Psicologia e Sociedade; 19 (1): 15-22, jan/abr. 2007.

KASTRUP, V. A aprendizagem da atenção na cognição inventiva, In: Revista Psicologia \& Sociedade/ABRAPSO, 2004, set/dez, vol.16, n. ${ }^{\circ} 3$.

SIBILIA, P. Redes ou Paredes: a escola em tempos de dispersão. Rio de Janeiro: Contraponto, 2012.

WULF, C. Homo Pictor: imaginação, ritual e aprendizado mimético no mundo globalizado. São Paulo: Hedra, 2013.

XAVIER, I. (entrevista). Um cinema que "educa" é um cinema que (nos) faz pensar. Educação e Realidade. 33(1): jan./jun. 2008.13 - 20.

\footnotetext{
i E-mail:danielegomess@live.com. Professora de Filosofia da Rede Estadual e Doutoranda no Programa de PósGraduação em Educação da Universidade Federal do Rio de Janeiro, Rio de Janeiro, Brasil. https://orcid.org/00000002-4949-0237
}

2 Mais informações e acesso as produções em: http://www.cinead.org/

${ }^{3}$ Cartografia também chamada de esquizoanálise, pragmática e micropolítica (DELEUZE e GUATTARI, Mil Platôs, 1995).

${ }^{4}$ Por conta dessa escolha metodológica que insere quem pesquisa no território investigativo, é importante o uso, em alguns momentos, nos verbos na primeira pessoa do singular.

${ }^{5}$ Disponível em: https://www.youtube.com/watch?v=i3iJih81lfg

${ }^{6}$ Disponível em: https://www.youtube.com/watch?v=t0s1mGQxhAI

${ }^{7}$ Disponível em: https://www.youtube.com/watch?v=RXi2Gjw3YbU aos 5:34.

${ }^{8}$ Disponível em: https://www.youtube.com/watch?v=ZXEpjYnp3r8

9 Tal procedimento, de contextualizar, tem inspiração na abordagem triangular proposta por Ana Mae Barbosa (1989, 2013), que propõe o ensino de artes orientado pela contextualização, apreciação e fazer. Mesmo não se tratando de uma aula de artes, a percepção do trabalho entende o cinema enquanto arte e entende que tal abordagem dialoga com as do trabalho, para que fossem estabelecidas outras conexões com os sujeitos e espaço-tempo em que tais obras foram produzidas.

${ }^{10}$ Disponível em: https://www.youtube.com/watch?v=rVT0w5416io 